\title{
Disposal of used optical disks utilizing thermally-excited holes in titanium dioxide at high temperatures: A complete decomposition of polycarbonate
}

\author{
Jin Mizuguchi and Toshihiro Shinbara \\ Department of Applied Physics, Graduate School of Engineering, Yokohama National University, \\ 240-8501 Yokohama, Japan
}

(Received 12 May 2004; accepted 25 June 2004)

\begin{abstract}
Disposal of used optical disks is an urgent requirement for electronic industries. We propose a decomposition system of polycarbonates (PC) (used as substrate materials for optical disks) that utilizes thermally-excited holes at high temperatures. The present system is based on an oxide semiconductor $\left(\mathrm{TiO}_{2}\right)$ heated at about $500{ }^{\circ} \mathrm{C}$ in combination with a molten state of PC. Molten PC chains are first adsorbed on the surface of $\mathrm{TiO}_{2}$ due to electrostatic interactions between positively charged oxygen vacancies in $\mathrm{TiO}_{2}$ and the polar carbonyl group of $\mathrm{PC}:|\mathrm{O}| \cdots \cdots \mathrm{O}^{\delta-}=\mathrm{C}^{\delta+}$. Adsorbed $\mathrm{PC}$ is then oxidized by thermally-excited holes in $\mathrm{TiO}_{2}$ and decomposed into small fragments, followed by their combustion in the presence of oxygen to give solely $\mathrm{H}_{2} \mathrm{O}$ and $\mathrm{CO}_{2}$. The decomposition mechanism has been discussed on the basis of nonstoichiometric properties of $\mathrm{TiO}_{2}$ at high temperatures together with adsorption behavior of PC on the surface of $\mathrm{TiO}_{2}$. (C) 2004 American Institute of Physics. [DOI: 10.1063/1.1784553]
\end{abstract}

\section{INTRODUCTION}

With the advent of information technologies revolution, optical disks are more and more used for information storage systems. Polycarbonates (PC) are almost uniquely used as substrates for rewritable as well as recordable optical disks. At present, there arises a problem of how to dispose used optical disks. We propose in this report a system which enables us to completely decompose PC by means of thermally-excited holes of $\mathrm{TiO}_{2}$ at high temperatures in combination with a molten state of PC. ${ }^{1}$

As is well known, the photocatalytic effect of semiconductors makes use of photogenerated holes for the decomposition of a variety of substances. Above all, titanium dioxide is widely known as an effective photocatalyzer as well as a material that exhibits the superhydrophilic effect upon irradiation. ${ }^{2}$ However, the above effect is quite inefficient in the visible region because of a large band gap of titanium dioxide (ca. $3.2 \mathrm{eV}$ ). On the other hand, we expect a large number of charge carriers produced at high temperatures, for example, $350{ }^{\circ} \mathrm{C}$ where PC melts into liquid. According to the theory of semiconductors, ${ }^{3}$ the number of charge carriers is given by the product of the Fermi-Dirac distribution function and the density of state in the conduction band or valence band. So we estimate approximately a ratio of the number of charge carriers at room temperature and $350{ }^{\circ} \mathrm{C}$, using the Boltzmann distribution function. The electron and hole concentrations ( $n_{e}$ and $n_{h}$, respectively) for intrinsic semiconductors are given by the equation: $n_{e}=n_{h}=n_{0} \exp \left(-E_{g} / 2 k T\right)$, where $E_{g}$ denotes the energy gap and $n_{0}$ the number of carriers at $E_{g}=0$. The number of carriers at room temperature and $\quad 350{ }^{\circ} \mathrm{C} \quad\left[n_{\mathrm{RT}}=n_{0} \exp \left(-E_{g} / 2 k T_{\mathrm{RT}}\right) \quad\right.$ and $n_{623 \mathrm{~K}}=n_{0} \exp \left(-E_{g} / 2 k T_{623}\right)$, respectively] gives a ratio of $n_{623 \mathrm{~K}} / n_{\mathrm{RT}} \approx 8.8 \times 10^{13}$, where $E_{g}=3.2 \mathrm{eV}$ (band gap of titanium dioxide of the rutile phase). A large number of holes are then expected to appear at high temperatures where most of the polymers are in molten states. Then, the oxidation by holes at the interface between $\mathrm{TiO}_{2}$ (solid) and polymers (solid) becomes the one at the solid/liquid interface, leading to an extremely efficient contact between $\mathrm{TiO}_{2}$ and molten polymers.

The above idea of completely decomposing $\mathrm{PC}$ into $\mathrm{H}_{2} \mathrm{O}$ and $\mathrm{CO}_{2}$ stems from the following accidental findings. ${ }^{4}$ In the course of our investigation on the uv/visible-active photocatalyst of $\mathrm{TiO}_{2}$, we found that photocatalytic $\mathrm{TiO}_{2}$ powders were immediately colored vivid yellow when a $\mathrm{TiO}_{2}$-dispersed film was prepared with $\mathrm{PC}$ using toluene as a solvent. ${ }^{4}$ To our surprise, our PC-coated $\mathrm{TiO}_{2}$ powders were found to release a huge amount of exothermic energies (ca. $1.85 \mathrm{~kJ} / \mathrm{g}$ ) in the temperature range between 200 and $400{ }^{\circ} \mathrm{C}$ as shown in Fig. 1(a). This energy is comparable with that of trinitrotoluene (TNT) explosives. ${ }^{5}$ The mechanism has been interpreted as being due to successive decomposition of molten PC due to thermally-excited holes at the surface of $\mathrm{TiO}_{2}{ }^{4}$ Then, we firmly believed that the present system could be utilized on recycles for the industrial disposal of used optical disks.

\section{EXPERIMENT}

\section{A. Materials and their properties}

Surface-untreated $\mathrm{TiO}_{2}$ (photocatalyst: ST-01) as well as surface-treated $\mathrm{TiO}_{2}$ (white pigment: Taipaque CR-80) were obtained from Ishihara Sangyo Kaisha. ST-01 is mostly of the anatase form while CR- 80 is solely of rutile. The specific surface of ST-01 and CR- 80 was about 300 and $10 \mathrm{~m}^{2} / \mathrm{g}$, respectively.

Since $\mathrm{TiO}_{2}$ is a nonstoichiometric oxide semiconductor in the form of $\mathrm{Ti}_{1+x} \mathrm{O}_{2}$ (where $x$ denotes the extent of deviation from the stoichiometric composition), there are a number of positively-charged, oxygen-deficient sites $(|\mathrm{O}| \cdot)$ as shown in Fig. 2: $\mathrm{O}^{--}$(lattice point) $\rightarrow 1 / 2 \mathrm{O}_{2}$ (gas) $+|\mathrm{O}|$. 
(a)

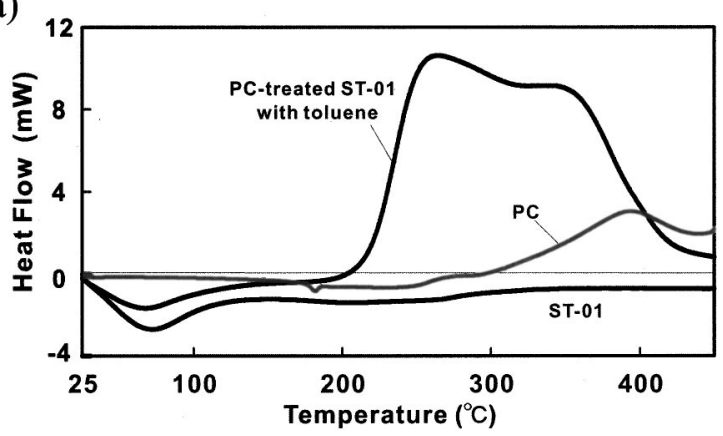

(b)

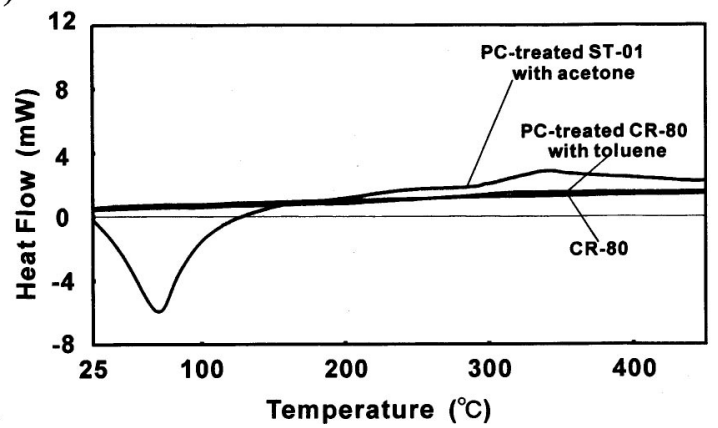

FIG. 1. DSC curves: (a) ST-01, PC-coated ST-01 with toluene and PC alone and (b) CR-80, PC-treated with acetone and PC-treated CR-80 with toluene.

$+2 \mathrm{e}^{-6,7}$ The two electrons released are weakly bound at low temperatures in the vicinity of the oxygen-deficient site with a Bohr radius of about $4 \AA$. At room temperature, however, the present donor is fully ionized to give up electrons to the conduction band, and thus an electrical conduction appears in proportion to the extent of nonstoichiometry designated by $x$ in $\mathrm{Ti}_{1+x} \mathrm{O}_{2}$. The free electrons are partly used for the reduction of oxygen molecules from the ambience, so that the oxygen molecules are ionically adsorbed on the surface of $\mathrm{TiO}_{2}$ in the form of $\mathrm{O}_{2}^{-}$radical: $\mathrm{O}_{2}$ (gas) $+\mathrm{e}^{-}=\mathrm{O}_{2}{ }^{-}$(ads). The existence of the $\mathrm{O}_{2}{ }^{-}$radical has already been verified by electron spin resonance measurements. ${ }^{8,9}$ The adsorbate $\mathrm{O}_{2}{ }^{-}$ then causes the upward band bending to occur that facilitates the accumulation of holes at the surface.

On the contrary, CR- 80 is surface coated with $\mathrm{Al}_{2} \mathrm{O}_{3}$ and $\mathrm{SiO}_{2}$ and is extremely inert. In other words, the active sites of $\mathrm{TiO}_{2}$ are completely filled with $\mathrm{Al}$ and $\mathrm{Si}$ oxides in CR-80. Therefore, CR-80 is widely used as a white pigment for paint industry.

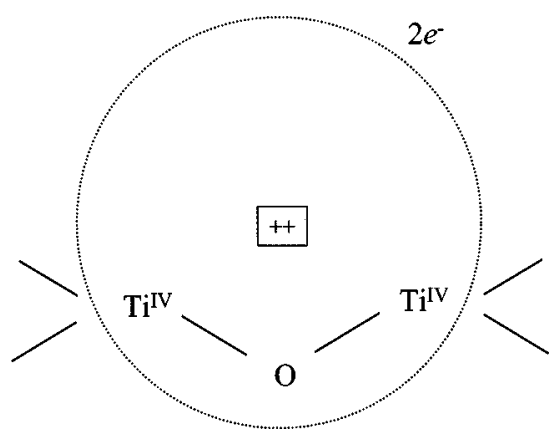

FIG. 2. Schematic representation of nonstoichiometric $\mathrm{TiO}_{2}: \mathrm{Ti}_{1+x} \mathrm{O}_{2}$ where $x$ denotes the extent of deviation from the stoichiometric composition.
A variety of PCs with molecular weights of 15000 120000 are on the market, depending on the applications. In the present experiment, PC of AD-5503 (used for optical disks; $M_{w}=$ about 18000 ) was obtained from Teijin Chemicals. Commercial PC normally contains several tens ppm of antioxidants as well as lubricants based on metallic soaps such as calcium salt. Teijin also supplied us with pure PC without any antioxidants.

\section{B. Preparation of PC-coated powders}

The following PC-coated samples were used for thermal measurements. PC (0.05 g) (AD-5503) was dissolved in $50 \mathrm{ml}$ of an organic solvent, followed by an addition of $0.95 \mathrm{~g}$ of $\mathrm{TiO}_{2}$ powders (ST-01 or Taipaque CR-80). The suspension was then filtered and the product was dried in air for several hours.

A 1:10 mixture (ST-01:AD-5503 in weight) was used for a large-scale experiment as well as for the analysis of evolved gases. A 2:1 mixture (in weight) of $\mathrm{TiO}_{2}$ (ST-01) and PC "with or without antioxidants" was also used for thermal measurements in order to study the effect of antioxidants.

\section{Measurements and equipment}

Heat flow was measured under nitrogen as a function of temperature by means of a differential scanning calorimeter (DSC) from Rigaku Ltd, (Thermo Plus: DSC8230). A mass spectrometer (JMS-AX500) from JEOL was used for the analysis of decomposed fragments of PC. A BET equipment (model: Multisorb 12) from Yuasa-Ionics Co. Ltd was employed for measurements of specific surface of $\mathrm{TiO}_{2}$ powders.

\section{RESULTS AND DISCUSSION}

\section{A. Coloration and discoloration of PC-coated $\mathrm{TiO}_{2}$}

As soon as the $\mathrm{TiO}_{2}$ powders (ST-01) were coated with PC using toluene as solvent, they were immediately colored yellow. The present coloration has already been clarified as the formation of a yellowish quinoid which is an oxidation product of stabilizers contained in PC. ${ }^{4,10-12}$ On the other hand, no coloration occurred with acetone. The yellowish color, however, disappeared in an hour when exposed to uv light (about $100 \mathrm{~W} / \mathrm{cm}^{2}$ ). On the contrary, the color remains unchanged upon irradiation with visible light in the wavelength region between 400 and $800 \mathrm{~nm}$. This evidently indicates that the band-to-band excitation (i.e., electron-hole formation) of $\mathrm{TiO}_{2}$ (397 nm for rutile and $377 \mathrm{~nm}$ for anatase) is responsible for the disappearance of the yellowish color; that is, decomposition of the quinoid compound by photogenerated holes. In contrast to the above result, no coloration took place in surface-coated $\mathrm{TiO}_{2}(\mathrm{CR}-80)$ powders even for the PC treatment with toluene or chloronaphthalene. This clearly indicates that the active sites due to oxygen vacancies in surface-untreated $\mathrm{TiO}_{2}(\mathrm{ST}-01)$ are directly involved in the coloration process. 


\section{B. DSC measurements}

Figure 1(a) shows the DSC curves for ST-01, PC-coated ST-01, and PC alone. In ST-01 powders, an endothermic band appears around $70^{\circ} \mathrm{C}$. This is due to desorption of adsorbed water as revealed from mass spectroscopic analysis. In contrast, PC-treated ST-01 exhibits a significant exothermic band in the range between 200 and $400{ }^{\circ} \mathrm{C}$. In addition, the endothermic peak around $70^{\circ} \mathrm{C}$ was also appreciably suppressed. The exothermic energy in the present temperature range was around $1.85 \mathrm{~kJ} / \mathrm{g}$ which is comparable with the explosion energy of TNT explosives. ${ }^{4}$ On the other hand, $\mathrm{PC}$ shows a small endothermic process in the range between 150 and $250{ }^{\circ} \mathrm{C}$, followed by an exothermic band around $380{ }^{\circ} \mathrm{C}$. PC is recognized to melt around $200{ }^{\circ} \mathrm{C}$ and to decompose around $350{ }^{\circ} \mathrm{C}$ as shown by the DSC curve [Fig. 1(a)]. Judging from the above results, it is evident that the huge amount of released energies of PCcoated ST-01 is not due to PC alone but due to a concerted effect as caused by ST-01, PC, and toluene treatment.

Figure 1(b) shows the DSC curve for PC-treated ST-01 powders with acetone together with the curve for CR-80 with and without PC treatment using toluene as a solvent. The former curve is characterized by an enhanced endothermic peak around $70{ }^{\circ} \mathrm{C}$ and a very broad exothermic band above $125^{\circ} \mathrm{C}$. The released energy is, however, quite small as compared with that of PC-treated ST-01 with toluene [Fig. 1(a)]. The present result clearly indicates that the solvent selection is crucial for the formation of a large amount of exothermic energies. On the contrary, neither endothermic nor exothermic effect was observed in surface-treated $\mathrm{TiO}_{2}$ $(\mathrm{CR}-80)$ in the range between 25 and $450{ }^{\circ} \mathrm{C}$. It follows that CR-80 is quite stable and insensitive to $\mathrm{PC}$ treatment with any solvent. This suggests that the existence of oxygen vacancies in $\mathrm{TiO}_{2}$ is indispensable for the appearance of tremendous exothermic energies.

\section{PC-decomposition process and analysis of evolved gases}

A 1:10 mixture of $\mathrm{TiO}_{2}$ and PC (ST-01: AD-5503 in weight) was heated at $500{ }^{\circ} \mathrm{C}$ in a crucible while monitoring the decomposition process. The PC decomposition proceeds visually as follows. The white powder of $\mathrm{TiO}_{2}$ becomes gradually dark brown in a minute and then PC decomposes in an instant, accompanied by gas evolution of a dark-red color. Finally, the powders come back to perfectly white. Figure 3 shows the comparison of the decomposition products of PC when heated in air at $500{ }^{\circ} \mathrm{C}$ for $10 \mathrm{~min}$ in the absence or presence of $\mathrm{TiO}_{2}$ powders. The left sample of "PC alone" melts at about $200{ }^{\circ} \mathrm{C}$ and then starts boiling. Finally, it ends up with carbonation characterized by a black color. On the other hand, PC decomposed completely in the presence of $\mathrm{TiO}_{2}$.

The gas evolved was analyzed by means of a mass spectrometer. Figure 4(a) shows the mass spectrum when the experiment was carried out in air. The spectrum is relatively simple and composed of mainly $\mathrm{N}_{2}$ and $\mathrm{O}_{2}$ arising from air, as well as $\mathrm{H}_{2} \mathrm{O}$ and $\mathrm{CO}_{2}$. The mass number of 14 is attributed to the $\mathrm{N}$ atom due to $\mathrm{HNO}_{3}$ used in the preparation of

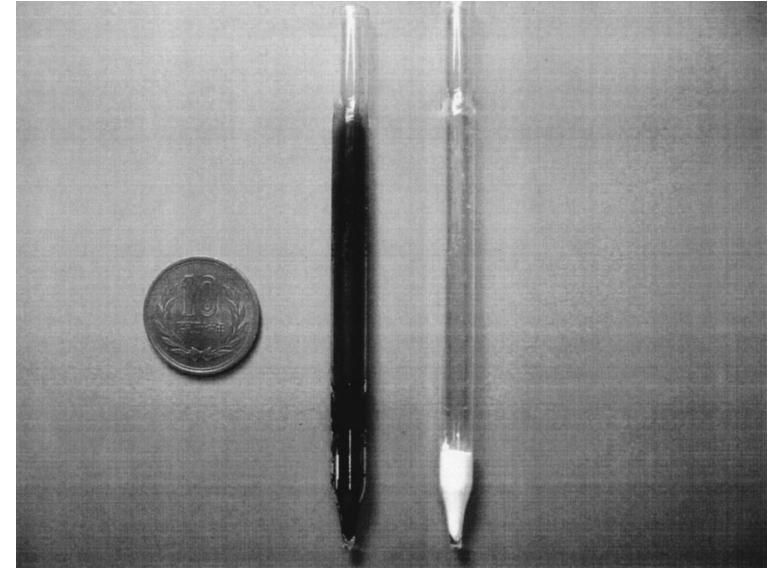

FIG. 3. Decomposition products of PC: (a) PC alone and (b) $\mathrm{PC}$ with $\mathrm{TiO}_{2}$.

fine powders of $\mathrm{TiO}_{2}$. The mass number of 44 is due to $\mathrm{Ca}$ used as a lubricant in the form of $\mathrm{Ca}$ soap. The dark-red gas which we saw was actually the color caused by flame reaction of $\mathrm{Ca}$. On the basis of the present analysis, we conclude that $\mathrm{PC}$ decomposes completely into $\mathrm{H}_{2} \mathrm{O}$ and $\mathrm{CO}_{2}$ in the presence of oxygen. On the other hand, the mass spectrum obtained under vacuum exhibits a variety of fragments as shown in Fig. 4(b). This indicates that the decomposition is incomplete in the absence of oxygen and that the presence of oxygen is indispensable for complete decomposition of PC. The above process leads us to suggest that PC decomposes first into small fragments due to oxidation by thermallyexcited holes and then the fragments burn with oxygen to give $\mathrm{H}_{2} \mathrm{O}$ and $\mathrm{CO}_{2}$.

\section{Adsorption of PC chains on the surface of $\mathrm{TiO}_{2}$ powders}

On the surface of $\mathrm{TiO}_{2}$ powders, electron-accepting oxygen acquires an electron from the bulk and is adsorbed there in the form of $\mathrm{O}_{2}^{-}$(ads). Under these circumstances, water

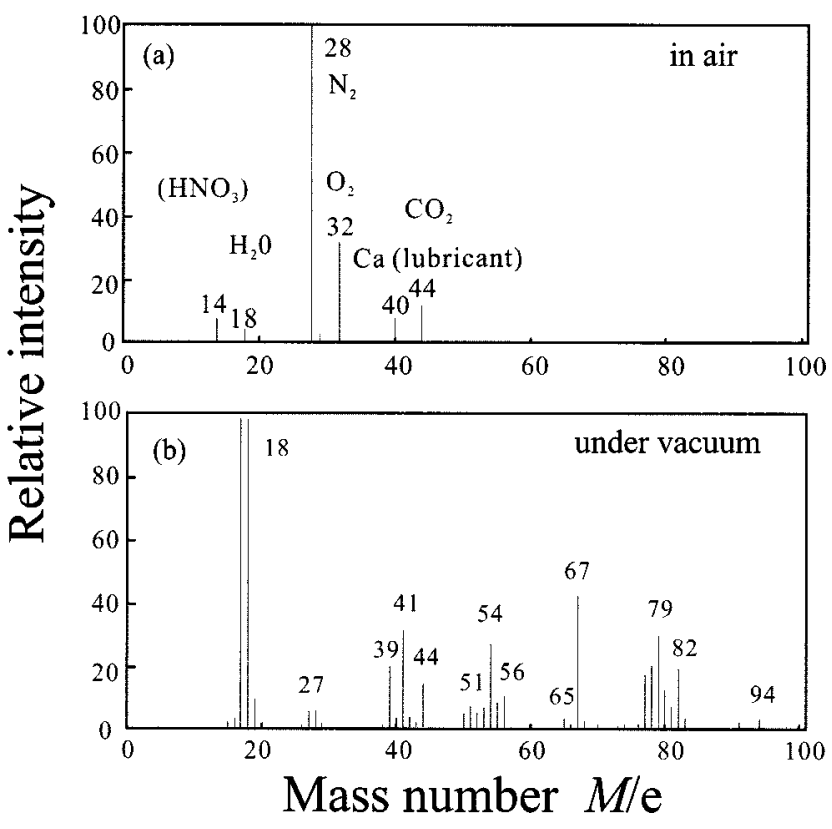

FIG. 4. Mass spectra of evolved gases: (a) in air and (b) under vacuum. 


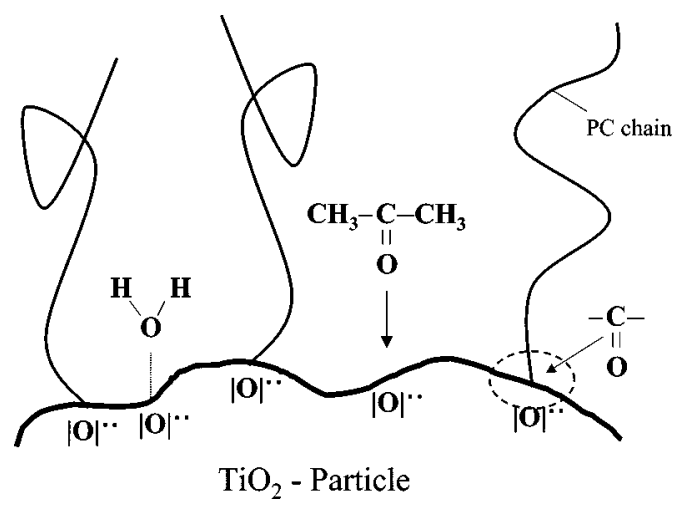

FIG. 5. Schematic representation of the adsorption of water, acetone, and $\mathrm{PC}$ on the oxygen-deficient sites $(|\mathrm{O}| \cdot)$ of $\mathrm{TiO}_{2}:|\mathrm{O}| \cdots \mathrm{O}^{\delta-} \mathrm{H}_{2}{ }^{\delta+}$ or $|\mathrm{O}| \cdots \cdots \mathrm{O}^{\delta-}=\mathrm{C}^{\delta+}$.

molecules can also be adsorbed on the surface of ST-01 in such a way that the oxygen-deficient site reacts electrostatically with the oxygen atom of water as shown in Fig. 5: $|\mathrm{O}| \cdots \cdots \mathrm{O}^{\delta-} \mathrm{H}_{2}{ }^{\delta+}$. Similarly, the $\mathrm{C}=\mathrm{O}$ group in $\mathrm{PC}$ is assumed to react with the oxygen-deficient site to form a surface complex: $|\mathrm{O}| \cdots \cdots \mathrm{O}^{\delta-}=\mathrm{C}^{\delta+}$.

When $\mathrm{PC}$ is dissolved in toluene for the preparation of PC-coated $\mathrm{TiO}_{2}$, the present powder releases a huge energy upon heating; whereas no appreciable exothermic energy was observed with acetone-treated powders [Fig. 1(b)]. This can be attributed to the preparation process of PC-coated powders. In toluene-based suspensions with $\mathrm{TiO}_{2}$, the carbonyl groups in PC are preferentially adsorbed on the oxygendeficient sites $\left(|\mathrm{O}| \cdots \cdots \mathrm{O}^{\delta-}=\mathrm{C}^{\delta+}\right)$, because there is no equivalent polar group in the toluene molecule to that of the carbonyl group. PC remains adsorbed on $\mathrm{TiO}_{2}$ even when toluene is vaporized in the drying process. Thus, PC can easily be oxidized by thermally-excited holes at high temperatures. On the other hand, there is a carbonyl group in the acetone molecule. Therefore, in acetone-based suspension with $\mathrm{TiO}_{2}$ powders, the carbonyl group of acetone competes with that of PC in an attempt to occupy the oxygen-deficient site (Fig. 5). This competing reaction ends up presumably with the preferential adsorption of acetone, because the acetone molecule is smaller than PC and thus more geometrically convenient for the specific adsorption on the surface of $\mathrm{TiO}_{2}$. When acetone is vaporized in the drying process, it leaves a space between PC and the oxygen-vacant site of $\mathrm{TiO}_{2}$. In other words, $\mathrm{PC}$ is not effectively adsorbed on the surface of $\mathrm{TiO}_{2}$. This situation is quite inconvenient for the surface reaction with holes upon heating.

\section{E. Raman spectra of $\mathrm{TiO}_{2}$}

Figure 6(a) shows the Raman spectrum for ST-01 powders. All peaks are assigned to the irreducible representations of the anatase phase. ${ }^{13}$ Among these, the peak around $145 \mathrm{~cm}^{-1}$ assigned to $E_{g}$ is quite sensitive to the surface treatment as shown in Fig. 6(b) where the ST-01 powders are variously treated. The peaks for untreated and acetonetreated powders are located at the same position. On the other hand, the toluene-treated powder exhibits a displacement toward higher wave numbers. This indicates that there
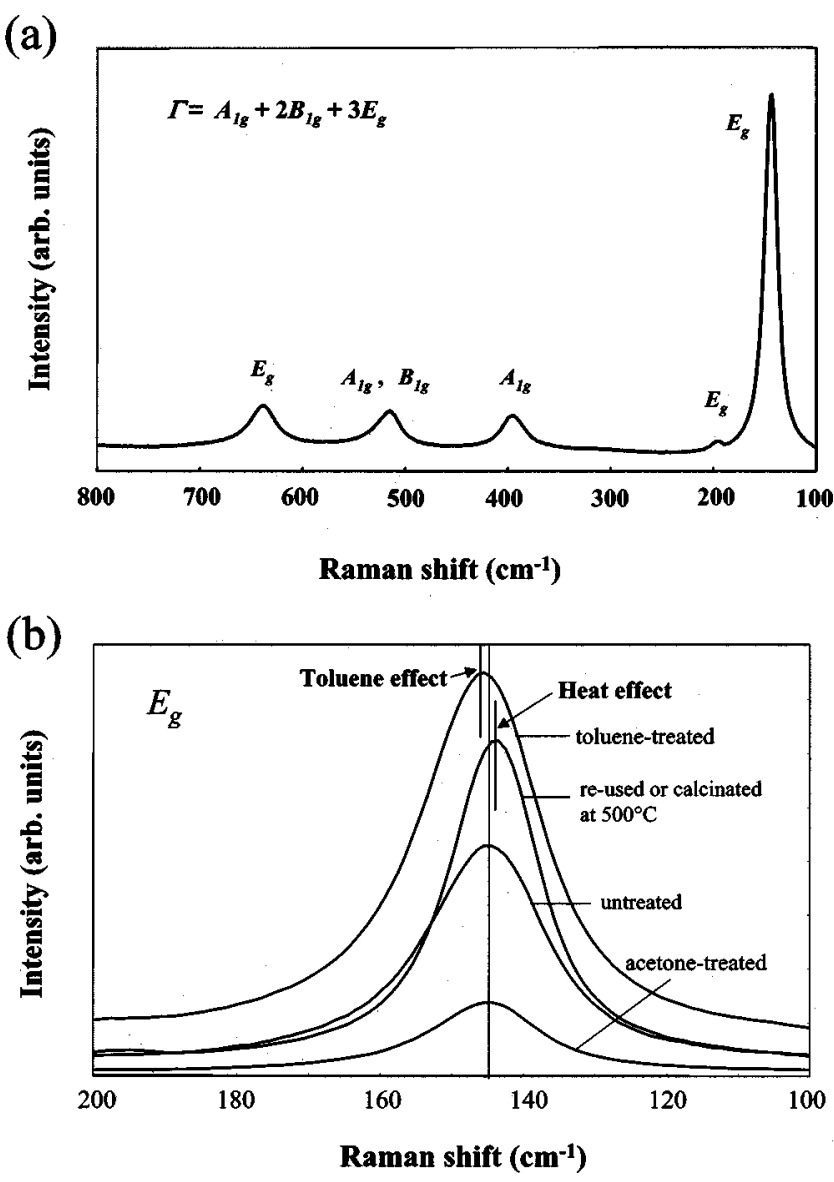

FIG. 6. Raman spectra: (a) untreated ST-01 and (b) variously treated ST-01.

is an interaction between $\mathrm{PC}$ and the surface of $\mathrm{TiO}_{2}$, suggesting that $\mathrm{PC}$ is firmly adsorbed on the surface of $\mathrm{TiO}_{2}$. It is also to be noted that the re-used powders or powders heated at $500{ }^{\circ} \mathrm{C}$ exhibit a Raman shift toward lower wave numbers. This is caused by improved crystallinity as well as the increase in particle size as shown by x-ray diffraction diagrams (Fig. 7).

Figure 7 shows the powder diffraction diagrams for reused or calcinated powders at $500{ }^{\circ} \mathrm{C}$ for $30 \mathrm{~min}$. The crystal phase at the initial state is typical of the anatase form as also assigned by the Raman spectrum [Fig. 6(a)], but not well

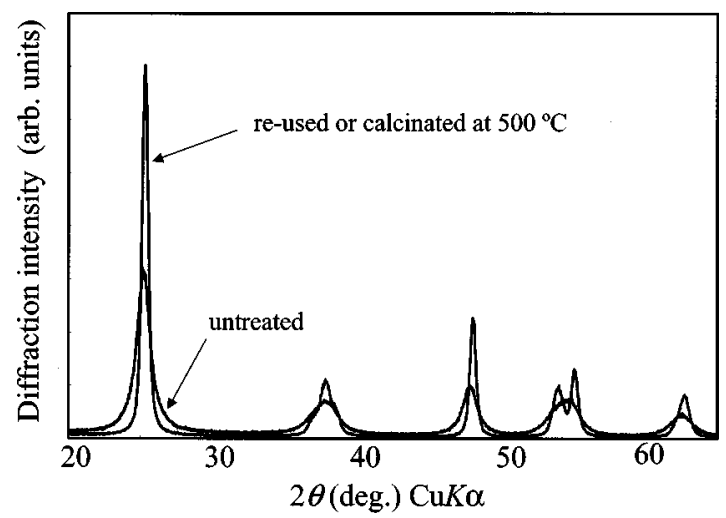

FIG. 7. Powder x-ray diffraction diagrams for untreated ST-01, re-used ST01 , and calcinated ST- 01 at $500{ }^{\circ} \mathrm{C}$. Re-used and calcinated ST-01 powders gave the same diffraction diagrams. 


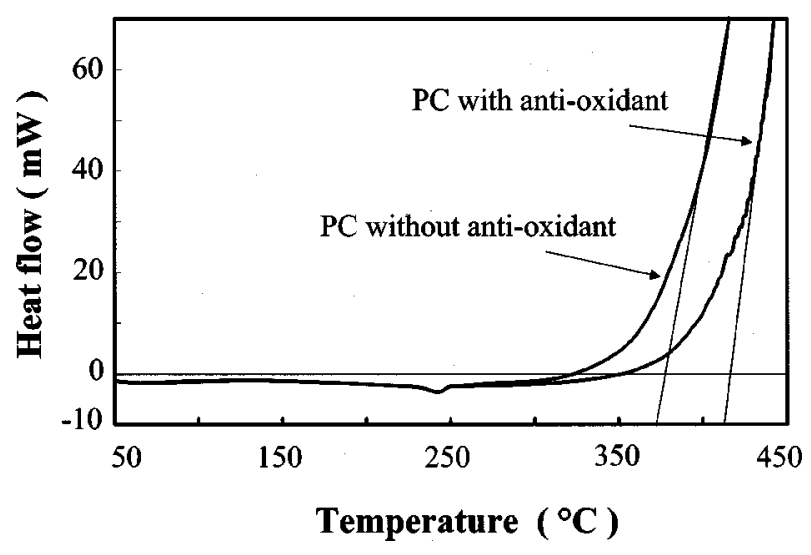

FIG. 8. Effect of antioxidants on the onset temperature of the DSC curve.

crystallized. Calcination at elevated temperatures makes the diffraction peaks narrower or split into two peaks, indicating the increase in crystallinity and crystal size.

\section{F. Effect of antioxidants}

The effect of antioxidants included in PC were studied by DSC. Figure 8 shows the DSC characteristics of $\mathrm{TiO}_{2}$ powders (ST-01) with PC in the presence or absence of antioxidants. It is apparent that the onset temperature of the exothermic curve in PC with antioxidant is higher than in PC without antioxidant, showing clearly the effect of antioxidation. Except for the present difference in the onset temperature, PC with or without antioxidant can be decomposed in the same way.

\section{G. Mechanism of PC decomposition in the presence of $\mathrm{O}_{2}$}

PC decomposition is assumed to proceed in three steps: adsorption of PC on the surface of $\mathrm{TiO}_{2}$, oxidation decomposition of $\mathrm{PC}$ into small fragments, and combustion of fragments with $\mathrm{O}_{2}$. Figure 9 shows our proposed mechanism of complete decomposition of $\mathrm{PC}$ into $\mathrm{H}_{2} \mathrm{O}$ and $\mathrm{CO}_{2}$. At about $350{ }^{\circ} \mathrm{C}$, there form a huge number of holes in $\mathrm{TiO}_{2}$ and $\mathrm{PC}$

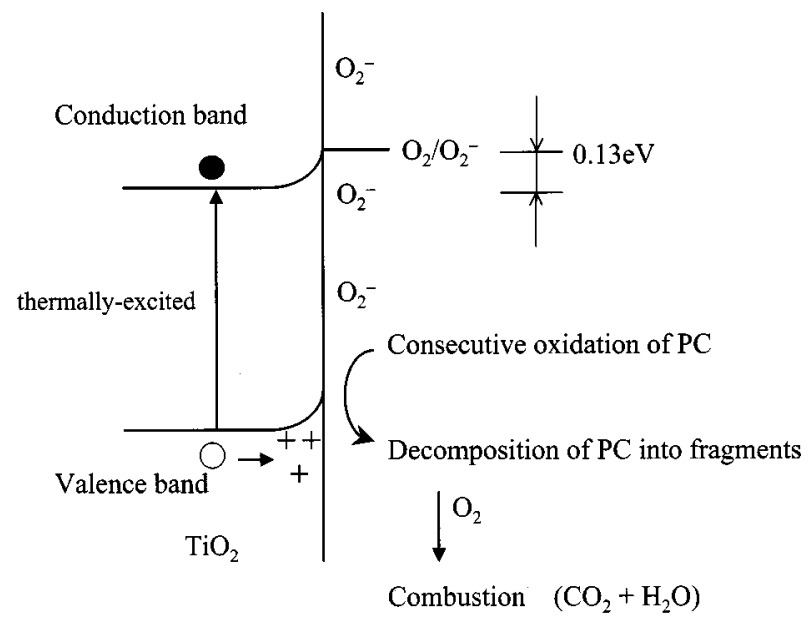

FIG. 9. Schematic illustration of the proposed mechanism for complete decomposition of $\mathrm{PC}$ at the interface between $\mathrm{TiO}_{2}$ and $\mathrm{PC}$ in the presence of oxygen.
TABLE I. Change in specific surface of powdered $\mathrm{TiO}_{2}$ due to calcination at various temperatures.

\begin{tabular}{cc}
\hline \hline Powdered $\mathrm{TiO}_{2}(\mathrm{ST}-01)\left({ }^{\circ} \mathrm{C}\right)$ & Specific surface $\left(\mathrm{m}^{2} / \mathrm{g}\right)$ \\
\hline Untreated & 278 \\
300 & 158 \\
400 & 116 \\
500 & 96 \\
\hline \hline
\end{tabular}

is also in molten state. The carbonyl groups of PC are electrostatically bonded to the oxygen-deficient site of $\mathrm{TiO}_{2}$ : $|\mathrm{O}| \cdots \cdot \mathrm{O}^{\delta-}=\mathrm{C}^{\delta+}$. The thermally-excited holes are accumulated at the surface of powders because of the upward bending of $\mathrm{TiO}_{2}$. Then, the holes oxidize $\mathrm{PC}$ into small fragments, followed by combustion with oxygen to give $\mathrm{H}_{2} \mathrm{O}$ and $\mathrm{CO}_{2}$. After completion of the first cycle, another $\mathrm{PC}$ chain in bulk is newly adsorbed on the oxygen-deficient site of $\mathrm{TiO}_{2}$ and likewise decomposed. In this way, the consecutive oxidation continues until PC is completely used up. On the other hand, the thermally-excited electrons are partly combined with thermally-excited holes and partly consumed to reduce oxygen $\left[\mathrm{O}_{2}+\mathrm{e}^{-} \rightarrow \mathrm{O}_{2}^{-}\right.$(ads) $]$to maintain the band bending at the surface while partly recombine with holes.

\section{H. Re-use of $\mathrm{TiO}_{2}$}

In the present system, $\mathrm{TiO}_{2}$ can be re-used repeatedly. For recycles, the specific surface of the powders should remain as large as possible, because the decomposition occurs at the interface between $\mathrm{TiO}_{2}$ and PC. In addition, the crystallinity also plays an important role in carrier mobility that governs the efficiency of the carrier transport to the surface.

Table I details the change in specific surface of $\mathrm{TiO}_{2}$ powders at 300,400 , and $500{ }^{\circ} \mathrm{C}$ in air for $1 \mathrm{~h}$. The surface area of ST-01 powder amounts to about $278 \mathrm{~m}^{2} / \mathrm{g}$, but decreases adversely with increasing temperature. Simultaneously, however, the crystallinity is significantly improved as shown by the x-ray diffraction diagrams (Fig. 7). Calcination brings about both the positive and negative effects in crystallinity and surface area, respectively. However, these two conflicting factors seem to compensate each other in practice. In fact, no noticeable deterioration of $\mathrm{TiO}_{2}$ in decomposition efficiency was recognized even when the recycle was made more than five times.

\section{CONCLUSIONS}

Use of thermally-excited holes in $\mathrm{TiO}_{2}$ has been investigated for complete decomposition of PC used as substrate materials for optical disks. PC is found to be decomposed into $\mathrm{H}_{2} \mathrm{O}$ and $\mathrm{CO}_{2}$ by means of thermally-excited holes in the presence of oxygen. PC decomposition is considered to proceed in three steps: adsorption of $\mathrm{PC}$ chains on the surface of $\mathrm{TiO}_{2}$, decomposition of PC into small fragments by holes, and subsequent combustion of fragments with oxygen. The present technology can also be used for industrial disposal of a variety of polymers as well as compounds such as chlorofluorocarbons, dioxins, polychlorobiphenyls, etc. 


\section{ACKNOWLEDGMENT}

This work was supported by a Grant-in-Aid for Scientific Research on Priority Areas (417) from the Ministry of Education, Culture, Sports, Science and Technology (MEXT) of the Japanese Government.

${ }^{1}$ J. Mizuguchi and T. Shinbara, Jpn. Pat. Application No. 2003-357616.

${ }^{2}$ R. Wang, K. Hashimoto, A. Fujishima, M. Chikuni, E. Kojima, A. Kitamura, M. Shimohigoshi, and T. Watanabe, Nature (London) 388, 431 (1997).

${ }^{3}$ C. Kittel, Introduction to Solid State Physics, 6th Ed. (Wiley, New York, 1986).

${ }^{4}$ J. Mizuguchi, J. Electrochem. Soc. 148, J55 (2001).

${ }^{5}$ Ullmann's Encyclopedia of Industrial Chemistry (VCH Verlag, Weinheim,
1982), Vol. 21, p. 661.

${ }^{6} \mathrm{~K}$. Hauffe and S. Roy Morrison, Adsorption (Walter de Gruyter, Berlin, 1974).

${ }^{7}$ S. Roy Morrison, in Surface Physics of Phosphors and Semiconductors, edited by C. G. Scott and C. E. Reed (Academic, New York 1975), Chap. 4.

${ }^{8}$ C. Naccache, P. Meriandean, M. Che, and T. Tench, Trans. Faraday Soc. 67, 506 (1971).

${ }^{9}$ K. M. Sancier, J. Catal. 9, 331 (1968).

${ }^{10}$ N. S. Allen, D. J. Bullen, and J. F. McKellar, J. Mater. Sci. 12, 1320 (1977).

${ }^{11}$ I. Jagnandan, H. Daun, T. J. Ambrosio, and S. G. Gilbert, J. Pharm. Sci. 68, 916 (1979).

${ }^{12}$ A. Dwight and E. I. Holtzen, Plast. Eng. (Brookfield, Conn.) 33, 43 (1977).

${ }^{13}$ U. Balanchandran and N. G. Eror, J. Solid State Chem. 42, 276 (1982). 